\title{
Krankenversicherung neu mit der Helsana Gruppe
}

\section{Profitieren Sie vom FMH Insurance Services Kollektivvertrag}

\section{FMH Insurance Services Kollektivvertrag}

Treten Sie dem FMH Insurance Services Kollektivvertrag bei, der mit der Helsana Gruppe abgeschlossen wurde. Die Helsana Gruppe besteht aus folgenden Versicherungsgesellschaften: Avanex, Helsana, Progrès und Sansan. Profitieren Sie und Ihre Familienmitglieder von den Topleistungen und den attraktiven Prämienrabatten.

\section{Ihre Vorteile auf einen Blick}

Kollektivrabatte bei Helsana 20\%

Helsana gewährt FMH-Mitgliedern auf die meisten Zusatzversicherungen einen Kollektivrabatt von $20 \%$ gegenüber der Normalprämie.

Kollektivrabatte bei Avanex, Progrès und Sansan 15\%

Die obengenannten Kassen gewähren FMH-Mitgliedern auf die meisten Zusatzversicherungen einen Kollektivrabatt von 15\% gegenüber der Normalprämie.

Sind Sie bereits bei einer Krankenversicherung der Helsana Gruppe versichert? Wechseln Sie ganz einfach und ohne grossen Aufwand in den FMH Insurance Services Kollektivvertrag. Rufen Sie uns an, damit auch Sie in Zukunft von günstigeren Konditionen profitieren können.

\section{Profitieren Sie von unserem Angebot}

Nutzen Sie die Vorteile des FMH Insurance Services Kollektivvertrags, und bestellen Sie noch heute Ihre persönliche Offerte mit dem untenstehenden Antworttalon (bitte eine aktuelle Policenkopie beilegen).

\section{Antworttalon}

Vorname / Name

Adresse

PLZ / Ort

Geburtsdatum

Telefon privat/Geschäft

Beste Zeit für einen Anruf

E-Mail-Adresse

Bitte senden Sie mir eine Offerte. (Bitte eine aktuelle Policenkopie beilegen!)

Ich wünsche eine persönliche Beratung.

Bitte rufen Sie mich an.

Ich interessiere mich für folgende Produkte:

Todesfallversicherung

Säule $3 a$

Finanz-/Steuerplanung

O

\footnotetext{
Pensionskasse BVG

Rechtsschutzversicherung

Berufshaftpflichtversicherung
}

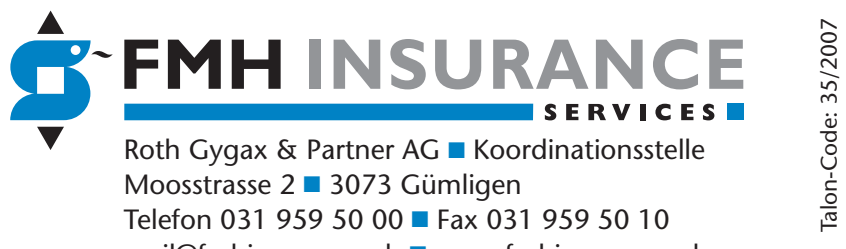

mail@fmhinsurance.ch $\square$ www.fmhinsurance.ch 